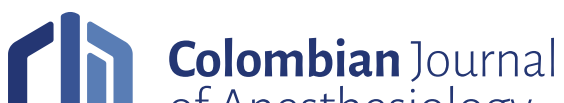 \\ of Anesthesiology
}

\section{Validity and reliability of the SBI (Spanish Burnout Inventory) in medical surgical specialists}

\section{Validez y confiabilidad del CESQT en médicos especiallistas quirúrgicos}

\author{
Luis Mauricio García Borrero ${ }^{a}$ (iD) , Daniel Camilo Aguirre Acevedo ${ }^{b}$ (D) , Carla María Zapata Ruedac (iD), \\ Héctor Iván García Garcíab (iD) \\ ${ }^{a}$ Master in Clinical Epidemiology, Universidad de Antioquia. Medellín, Colombia. \\ ${ }^{\mathrm{b}}$ Clinical Epidemiology Academic Group, Medical Research Institute, School of Medicine, Universidad de Antioquia. Medellín, Colombia. \\ 'Department of Psychology, Universidad de San Buenaventura. Medellín, Colombia.
}

Correspondence: Cra. 43A No. 1sur-100, piso 20, Edificio Sudameris. Medellín, Colombia. E-mail: mauroanes@yahoo.com

\section{Abstract}

\section{What do we know about}

this topic?

Burnout Syndrome (BOS) is a syndrome derived from chronic stress in the workplace that was not successfully managed.

\section{What new does this study contribute with?}

In Colombia, there is no a validated instrument that can be used to measure the BOS on health human talent. Therefore, this validation and reliability study of the Spanish Burnout Inventory (SBI) for burnout assessment will contribute this validated tool for further studies.

How to cite this article:

García Borrero LM, Aguirre Acevedo DC, Zapata Rueda CM, García García HI. Validity and reliability of the SBI (Spanish Burnout Inventory) in medical surgical specialists. Colombian Journal of Anesthesiology. 2022;50:e1017.

\section{Introduction}

Burnout Syndrome is the term used to describe the psychological response to patient carerelated chronic work stress. Studies have found that the prevalence of practitioner burnout in Colombia ranges between $17.6 \%$ and $45 \%$. Given the importance of this phenomenon in our setting, we decided to carry out a validation and reliability study of the Spanish Burnout Inventory $(\mathrm{SBI})$.

\section{Objective}

To assess the validity and reliability of the SBI in medical surgical specialists working in fourteen health care facilities in Antioquia (Colombia) in 2018.

\section{Methods}

The study was conducted in 14 healthcare institutions among 8 surgical specialties. The tool consists of 20 items collected by means of face-to-face interviews under the supervision of a psychologist, and maintaining confidentiality. The psychometric assessment included content validity (CV), construct validity using confirmatory factor analysis (CFA) and reliability using Cronbach's Alpha.

\section{Results}

The study sample consisted of 234 participants. CV of the tool was 0.82 . The CFA showed acceptable model fit, with the results of goodness-of-fit being $x 2=384.578$ ( $p<0.001 ; \mathrm{df}: 165$ ), RMSEA $=0.075$ [90\% $\mathrm{Cl}: 0.066-0.085], \mathrm{CFI}=0.953, \mathrm{TLI}=0.946$ and $\mathrm{WRMR}=1.074$. The SBI Cronbach's alpha was 0.79.

\section{Conclusions}

The SBI showed acceptable CV levels for all the items and domains. The SBI is a valid tool with adequate reliability for use in medical surgical specialists of healthcare institutions in AntioquiaColombia.

\section{Keywords}

CESQT; Burnout Syndrome; Spanish Burnout Inventory; Medical surgical specialists; Anesthesiology 


\section{Resumen}

Introducción

El síndrome de Quemarse por el Trabajo es la respuesta psicológica al estrés laboral crónico relacionado con la atención de pacientes. La prevalencia del síndrome en médicos colombianos varía entre el $17 \%$ y el $45 \%$, usando cuestionarios no validados.

\section{Objetivo}

Evaluar la validez y fiabilidad del Cuestionario para la Evaluación del Síndrome de Quemarse por el Trabajo (CESQT), en médicos especialistas quirúrgicos que laboraban en instituciones de salud de Antioquia, Colombia en 2018.

\section{Métodos}

El estudio se realizó en 14 instituciones hospitalarias con 8 especialidades quirúrgicas, el instrumento consta de 20 ítems cuya recolección se hizo presencial, supervisado por una psicóloga, manteniendo la confidencialidad; la evaluación psicométrica incluyó validez de contenido (VC), validez de constructo mediante análisis factorial confirmatorio (AFC) y fiabilidad con alfa de Cronbach.

\section{Resultados}

Se encuestaron 234 especialistas. La VC del instrumento fue de 0,82 . Los índices de bondad de ajuste en el AFC fueron: $X 2=384,578$ ( $p<0,001 ; g)$ : 165), RMSEA =0,075 [IC $90 \%$ : 0,066-0,085], CFI = 0,953, TLI = 0,946 y WRMR =1,074. El alfa de Cronbach fue 0,79.

\section{Conclusiones}

EI CESQT tiene niveles aceptables de VC para los ítems y sus dimensiones. El CESQT es un instrumento válido con adecuada fiabilidad para ser utilizado en médicos especialistas quirúrgicos de instituciones de salud de Antioquia, Colombia.

\section{Palabras clave}

CESQT; Síndrome Burnout; Spanish Burnout Inventory; Médicos especialistas quirúrgicos; Anestesiología.

\section{INTRODUCTION}

Burnout syndrome (BOS) is the term used to describe a response to chronic stressors at work and may occur in individuals providing patient care (1-3). This syndrome was first described in 1974 by Helbert Freudenberg in New York (4).

The World Health Organization (WHO) has highlighted the importance of human resources as critical for quality healthcare $(5)$ and included burnout in its 11th revision of the International Classification of Diseases (ICD-11) describing it as an occupational exhaustion syndrome. The WHO defines it, not as a disease, but as a syndrome derived from chronic workplace stress that has not been successfully managed, and the term must not be applied to describe experiences in other areas of life (6).

In the world, the incidence of $\mathrm{BOS}$ among physicians is close to $28 \%(7)$. In Colombia, the prevalence of BOS in medicine ranges between $17.6 \%$ and $45 \% \underline{(8,9)}$.
In 2006, Gil-Monte designed the questionnaire for workplace burnout assessment, which includes four domains: enthusiasm toward the job (It), understood as the achievement of goals that are perceived as creating a feeling of enjoyment and personal satisfaction; mental exhaustion (Dp), consisting of emotional and physical exhaustion derived from care-related activities; indolence (In), which refers to the presence of negative attitudes such as cynicism, indifference and callousness towards the people served; guilt (C), as the feeling that emerges as a result of the individual's own behavior or work-related negative attitudes, mainly towards people with whom relations are established at work. The SBI is summarized in the form of two different profiles, depending on whether the guilt domain is included or not $(10,11)$.

Human resources working in health care may suffer from high levels of anxiety, depression, suicide and BOS due to work overload or stress. The SBI has been shown to be useful for diagnosing BOS in countries such as Spain, Mexico and Brazil (12-14); however, it has not been validated yet in Colombia.

The objective of this study was to assess content and construct validity (CV) and reliability of the SBI in surgical specialists working in healthcare institutions in Antioquia, Colombia in 2018.

\section{MATERIALS AND METHODS}

The SBI validation and reliability study was approved by the Ethics Committee of the Universidad de Antioquia Medical Research Institute as stated in Minutes No. 088 of May 24,2018 , and by the committees of each of the participating institutions. The study complied with the current regulations on human research, in particular Resolution 8430 of 1993 of the Colombian Ministry of Health and the 2013 Declaration of Helsinki on human research. The study was classified as minimum risk. 
The SBI copyrights were purchased directly from the TEA Ediciones representative in Colombia; the author gave permission to use the tool. Data were collected in a database using a Google docs form, with doble entry in Windows Excel. The SPSS 23 and MPlus 8 statistical software packages were used for data analysis (15).

\section{Participants}

The participants were Colombian physicians from eight surgical specialties working in 14 healthcare institutions located in the department of Antioquia, Colombia. Participants were recruited between June 27 and September 4, 2018.

\section{Sample selection}

Of the 415 surgical specialists working in the 14 healthcare institutions, a sample of 220 , stratified by specialty, was selected; convenience sampling was used among those who agreed to participate.

Inclusion criteria: Colombian nationals practicing a surgical specialty such as anesthesiology, surgery, pediatric surgery, obstetrics and gynecology, neurosurgery, orthopedics, urology and otolaryngology, with more than six months of experience in their surgical specialty.

Exclusion criterion: surgical specialist working only in an administrative role.

The sample size was estimated based on the need to recruit at least 10 subjects for each item as proposed by Kline, and at least 200 as the ideal minimum for performing a factorial analysis, as suggested by Ferrando and Anguiano $(16,17)$. For reliability of the sample size based on internal consistency, a number ranging between 5 and 20 participants for each questionnaire item was estimated. In this case, considering that the SBI has 20 items, the sample of 200 participants was sufficient for the analysis (18-20). Potential data attrition was estimated at $10 \%$, for a total of 220 participants.

\section{Pilot test}

The pilot test was conducted with 11 volunteer healthcare professionals not included in the study, under the supervision of a psychologist with training in the use of the tool.

\section{Tool}

The $\mathrm{SBI}$ is a questionnaire used to assess cognitions, emotions and attitudes related to individual workplace experiences. It consists of 20 items covering four domains: enthusiasm toward the job, psychological exhaustion, indolence and guilt. Each item is assigned a frequency of 0 to 4 , where 0 is never; 1 is rarely, sometimes during the year; 2 is sometimes, at times during the month; 3 is frequently or sometimes during the week; and 4 is very frequently, every day $(10,21)$. Direct scores for each domain and total scores are found in healthcare personnel table of rates of the SBI Manual and are used to derive percentiles for each domain and the total BOS. The Guilt domain is interpreted independently and its items are not part of the total SBI score. The aim is to distinguish between two profiles: Profile 1 which indicates BOS symptoms without guilt regarding patient care; and Profile 2 that reflects a critical BOS level with Guilt (percentile $\geq 90$ ).

The SBI uses four cutoff points for interpreting the scores, based on percentiles: very low <11; low, 11 to 33; medium, 34 to 66 ; high, 67 to 89; and critical >89 (10).

A psychologist supervised full completion of the tool by the specialists who were working at the time of the visit to each institution, ensuring privacy, willingness and data confidentiality as well as control of missing data.

\section{Statistical analysis}

Categorical sociodemographic and work variables (gender, marital status, medical-surgical specialty, type of work contract and leisure time activity, enthusiasm towards the job, psychological exhaustion, indolence, guilt, total BOS) were summarized as absolute and relative frequencies; for quantitative variables (age, number of children, years of experience, total working hours per month, weekend hours worked per month, night shifts per month) mean and standard deviation or median and inter-quartile range were used according to whether data distribution was symmetrical or not. Floor and ceiling effect was estimated for each domain and also in the total SBI score, when more than $15 \%$ of the participants obtained the lowest or the highest score, respectively (22).

Content validity. Lawshe's critical content validity ratio (CVR) was used for each item, as it is accepted above the lower critical level of 0.622 for 7 experts, according to Schipper (assessed by the psychiatrist, psychologist and social worker by e-mail), with a one-tail normal approximation and a: 0.05; once the critical CVR for all the items was calculated, the content validity index (CVI) was estimated for those that are accepted, with a total scale acceptability level $\geq 0.8 \underline{(23-29)}$.

Construct validity. Construct validity was assessed using the confirmatory factorial analysis (CFA) (15), with a model specified in advance (10), supported on the questionnaire validation studies with four domains that were used as separate latent, albeit correlated, factors. The Weighted Least Squares Mean and Variance adjusted estimation method was used (30); the model's overall goodness of fit was evaluated, with $x_{2}(p>0.05)$, estimating the ratio between its value and the degrees of freedom. Other indices estimated the overall error quantity in the model: Root Mean Squared Error of Approximation (RMSEA), Comparative Fit Index (CFI), Tucker-Lewis Index (TLI) and the Weighted Root Mean Square Residual (WRMSR). The RMSEA index quantified data divergence, where a value of $<0.06$ indicated good fit, while values up to 0.08 , with $90 \% \mathrm{Cl}$, represented acceptable fit. For $\mathrm{CFI}$ and TLI, values $\geq 0.95$ were considered as acceptable 
model fit; for WRMR, values < 0.9, with model fit acceptability; for variables, considering their categorical nature, a polychoric correlation was used $\underline{(31,32)}$.

Reliability. Reliability was evaluated for domains and for the total scale, assessing item-item, item-domain and item-scale internal validity using Cronbach's alpha coefficient and its $95 \%$ confidence interval; Cronbach's alpha coefficient between 0.7 and 0.9 indicates good reliability; low values refer to poor homogeneity of the scale, as it may be assessing different aspects or conditions due to poor itemto-item correlation; and values above 0.9 reflect an exceedingly homogenous scale, with potential redundancy or item duplication $\underline{(19,20,33)}$.

\section{RESULTS}

\section{Sample description}

The sample was collected in 14 hospitals in Antioquia and consisted of 246 medicalsurgical specialists; 12 participants were excluded ( 5 with different nationality, 2 with a different specialty, and 5 who declined to participate), leaving 234 for the analysis; the sociodemographic characteristics of the participants are summarized in Table 1.

No floor or ceiling effect was found; only the Enthusiasm Towards the Job domain showed a ceiling effect in $25.2 \%$ of the respondents. There were no missing data in the assessment.

\section{Content validity (CV)}

$\mathrm{CV}$ was determined using the content validity index (CVI) with relevance, pertinence and sufficiency criteria applied to all the items. All items are accepted since they are above the lower critical level of 0.622 for seven experts (Table 2).

Once the critical CVR for all items was estimated, the CVI was estimated for the entire test, with an acceptability of 0.82 .
TABLE 1. Sociodemographic and work characteristics of medical-surgical specialists working in 14 healthcare institutions included for SBI validation and reliability in Medellin, Colombia, 2018.

\begin{tabular}{|c|c|c|}
\hline Variable name & Mean & SD \\
\hline Age (years) & 44.9 & 10.46 \\
\hline Number of children & 1.17 & 1.14 \\
\hline \multicolumn{3}{|c|}{ Median } \\
\hline Years of experience & 10 & $5.0-20$ \\
\hline Number of workplaces & 2 & $2-3$ \\
\hline Hours worked/month & 240 & $200-300$ \\
\hline Hours worked/week-ends & 36 & $18-55.5$ \\
\hline Hours worked/nighttime & 26 & $0.0-70$ \\
\hline \multicolumn{3}{|c|}{ Absolute frequency } \\
\hline \multicolumn{3}{|l|}{ Gender } \\
\hline Female & 43 & 18.4 \\
\hline Male & 191 & 81.6 \\
\hline \multicolumn{3}{|l|}{ Marital status } \\
\hline Single & 54 & 23.1 \\
\hline Married & 138 & 59 \\
\hline Free union & 27 & 11.5 \\
\hline Separated & 15 & 6.4 \\
\hline \multicolumn{3}{|l|}{ Surgical specialty } \\
\hline Anesthetist & 84 & 35.9 \\
\hline Surgeon & 38 & 16.2 \\
\hline Pediatric surgeon & 7 & 3.0 \\
\hline Obstetrician and gynecologist & 31 & 13.2 \\
\hline Orthopedist & 38 & 16.2 \\
\hline Neurosurgeon & 11 & 4.7 \\
\hline Urologist & 17 & 7.4 \\
\hline Otolaryngologist & 8 & 3.4 \\
\hline \multicolumn{3}{|l|}{ Type of contract } \\
\hline Non-fixed term & 84 & 35.9 \\
\hline Fixed term & 17 & 7.3 \\
\hline Service contract & 66 & 28.2 \\
\hline Union & 67 & 28.6 \\
\hline \multicolumn{3}{|l|}{ Leisure time activity } \\
\hline Reading & 111 & 47.4 \\
\hline Sports & 108 & 46.2 \\
\hline Family & 183 & 78.2 \\
\hline Movies and TV & 86 & 36.8 \\
\hline Travel & 13 & 5.6 \\
\hline Friends & 3 & 1.3 \\
\hline Others & 47 & 20.1 \\
\hline \multicolumn{3}{|l|}{ Healthcare institution } \\
\hline Institution 1 & 28 & 12 \\
\hline Institution 2 & 7 & 3 \\
\hline Institution 3 & 12 & 5.1 \\
\hline Institution 4 & 22 & 9.4 \\
\hline Institution 5 & 30 & 12.8 \\
\hline Institution 6 & 5 & 2.1 \\
\hline Institution 7 & 14 & 6 \\
\hline Institution 8 & 8 & 3.4 \\
\hline Institution 9 & 20 & 8.5 \\
\hline Institution 10 & 12 & 5.1 \\
\hline Institution 11 & 14 & 6 \\
\hline Institution 12 & 49 & 20.9 \\
\hline Institution 13 & 7 & 3 \\
\hline Institution 14 & 6 & 2.6 \\
\hline
\end{tabular}

+Shapiro Wilk normality test $(p<0.05)$. Me: Median; Q1: first quartile; Q3: third quartile; SD: Standard Deviation; \%: Percentage. SourCE: Authors. 


\section{Structural validity}

The CFA results for construct validity were based on a reflective model where global goodness of fit indices were $X_{2}=384,578$ ( $p<0.001$; degrees of freedom [df]: 165). The $\mathrm{x} 2 / \mathrm{gdf}$ ratio was calculated at 2.3 and, considering that it is above 2 , it indicates that there is no fit for the model with that test; the RMSEA $=0.075$ [90\% Cl: $0.066-$ 0.085 ]. The remaining indices are shown in Figure 1, where an acceptable model fit is observed. Acceptable data fit was found for the CFA model in the first contrast for the selected sample using all of the fit indices. There was no need to modify the model or to delete or remove items. As shown in Figure 1, all of the values for the standardized coefficients are high, the lowest being found for item 4 of the Guilt domain (0.62) and the highest for item 18 of the Psychological Exhaustion domain.

TABLE 2. Lawshe's critical CVR according to Schipper in the Enthusiasm Towards the Job, Psychological Exhaustion, Indolence and Guilt domains.

\begin{tabular}{|c|c|c|c|c|}
\hline Domain & Item & Relevance & Pertinenence & Sufficiency \\
\hline \multirow{5}{*}{$\begin{array}{l}\text { Enthusiasm } \\
\text { towards the job }\end{array}$} & 1 & 1.00 & 1.00 & \multirow{5}{*}{0.71} \\
\hline & 5 & 1.00 & 1.00 & \\
\hline & 10 & 1.00 & 1.00 & \\
\hline & 15 & 1.00 & 1.00 & \\
\hline & 19 & 0.71 & 0.71 & \\
\hline \multirow{4}{*}{$\begin{array}{l}\text { Psychological } \\
\text { exhaustion }\end{array}$} & 8 & 1.00 & 1.00 & \multirow{4}{*}{0.86} \\
\hline & 12 & 0.71 & 1.00 & \\
\hline & 17 & 1.00 & 0.71 & \\
\hline & 18 & 1.00 & 1.00 & \\
\hline \multirow{6}{*}{ Indolence } & 2 & 1.00 & 1.00 & \multirow{6}{*}{0.71} \\
\hline & 3 & 1.00 & 0.71 & \\
\hline & 6 & 0.71 & 0.71 & \\
\hline & 7 & 1.00 & 1.00 & \\
\hline & 11 & 0.71 & 0.71 & \\
\hline & 14 & 0.71 & 1.00 & \\
\hline \multirow{5}{*}{ Guilt } & 4 & 1.00 & 1.00 & \multirow{5}{*}{0.86} \\
\hline & 9 & 1.00 & 1.00 & \\
\hline & 13 & 0.71 & 0.71 & \\
\hline & 16 & 1.00 & 1.00 & \\
\hline & 20 & 1.00 & 1.00 & \\
\hline
\end{tabular}

Lower critical level of 0.622 for 7 experts according to Schipper with a one-tailed normal approximation a 0.05 . SOURCE: Authors.

\section{Reliability}

Cronbach's alpha was used to assess reliability, showing adequately homogenous values with no data redundancy or duplication; as illustrated in Table 3, Cronbach's alpha was above 0.7 for all domains, as was also true for all the 20 items of the SBI scale at 0.777 and $95 \% \mathrm{Cl}[0,733-0,816]$. Therefore, the whole questionnaire as well as each of the domains were found to be reliable for measuring BOS.

\section{Exploratory results}

An exploratory calculation was performed with the aim of determining the level of burnout among the participants; of the 234 respondents, it was found that $24(10.3 \%)$

\section{DISCUSSION}

The objective of this study was to assess content and construct validity, as well as consistency-type reliability of the SBI in surgical specialists working in 14 hospitals in Antioquia, during 2018. In a sample of 234 respondents, results showed that the scale is valid and reliable.

In 1981, Maslach and Jackson developed the Maslach Burnout Inventory (MBI) with three domains: emotional exhaustion, depersonalization and a low sense of professional accomplishment $(2,34)$; as for its limitations, it lacks a common cutoff criterion to determine the diagnosis, and the Depersonalization domain has a low reliability index; the Spanish language has psychometric weaknesses and low discrimination validity (35).

Results show an acceptability of $82 \%$ for the content validity index (CVI) for the overall test, meeting the acceptability criterion above the critical level of 0.622 for seven experts $(26,28)$; in contrast, in the thesis by Peñalosa who used the SBI as a measurement tool and assessed the CVI among five reviewers, item 16 "I think I should apologize to someone for my behavior" in the relevance variable, the CVI is 0.7 , failing to meet the content validity criterion $\underline{(36)}$.

Using the WLSMV method, the estimated fit indices for CFA confirm acceptably the hypothesis of the overall SBI fit to the observed data, mainly for RMSEA, CFI and TLI, which is consistent with the findings by Gil-Monte in 2011 for CFA with 9080 participants using the maximum likelihood method (ML), with adequate model fit and the following overall fit results: $X 2=3126.75$ ( $p=0.001 ; d f: 164)$; RMSEA $=0.045 ; \mathrm{CFI}=0.947 ; \mathrm{NFI}: 0.945 ;$ and CFI: $0.965 \underline{(10)}$.

As far as correlations with the four domains of the $\mathrm{SBI}$ are concerned, the 
FIGURE 1. Factorial model for the SBI in physicians with surgical specialty.

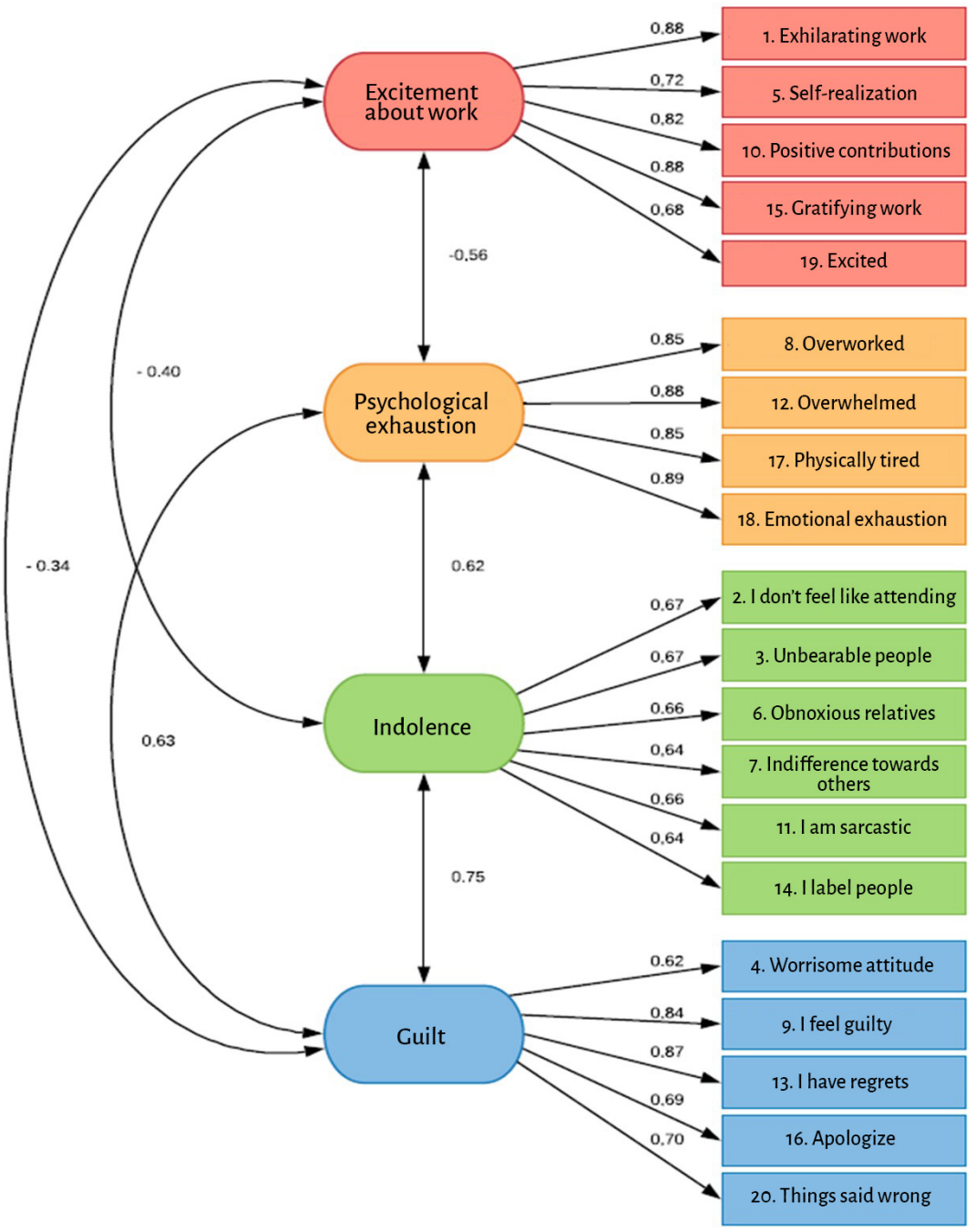

Clobal goodness of fit index for the hypothesized model: $\mathrm{CFI}=0.953, \mathrm{TLI}=0.946$ and WRMR $=$ 1.074. SOURCE: Authors.

TABLE 3. Reliability using Cronbach's alpha for the SBI domains.

\begin{tabular}{|c|c|c|}
\hline SBI - Dimensiones & Alfa de Cronbach* & IC 95\% \\
\hline Ilusión por el Trabajo & 0.789 & {$[0.744-0.829]$} \\
\hline Desgaste Psíquico & 0.897 & {$[0.874-0.917]$} \\
\hline Indolencia & 0.750 & {$[0.697-0.797]$} \\
\hline Culpa & 0.792 & {$[0.746-0.831]$} \\
\hline Total SBI & 0.777 & {$[0.733-0.816]$} \\
\hline
\end{tabular}

"Cronbach's alpha for the total SBI does not include Guilt.

SOURCE: Authors.
TABLE 4. Distribution of SBI levels among all the medical-surgical specialists of the 14 healthcare institutions in Medellín, Colombia, 2018.

\begin{tabular}{|c|c|c|}
\hline SBI Levels & $\begin{array}{l}\text { Absolute } \\
\text { frequency }\end{array}$ & $\%$ \\
\hline \multicolumn{3}{|l|}{$\begin{array}{c}\text { Enthusiasm towards } \\
\text { the job }\end{array}$} \\
\hline Critical & 0 & 0 \\
\hline High & 92 & 39.3 \\
\hline Medium & 112 & 47.9 \\
\hline Low & 24 & 10.3 \\
\hline Very low & 6 & 2.6 \\
\hline \multicolumn{3}{|l|}{$\begin{array}{l}\text { Psychological } \\
\text { exhaustion }\end{array}$} \\
\hline Critical & 16 & 6.8 \\
\hline High & 29 & 12.4 \\
\hline Medium & 93 & 39.7 \\
\hline Low & 50 & 21.4 \\
\hline Very low & 46 & 19.7 \\
\hline \multicolumn{3}{|l|}{ Indolence } \\
\hline Critical & 18 & 7.7 \\
\hline High & 42 & 17.9 \\
\hline Medium & 96 & 41.0 \\
\hline Low & 50 & 21.4 \\
\hline Very low & 28 & 12.0 \\
\hline \multicolumn{3}{|l|}{ Total SBI in health } \\
\hline Critical & 12 & 5.1 \\
\hline High & 24 & 10.3 \\
\hline Medium & 103 & 44.0 \\
\hline Low & 60 & 25.6 \\
\hline Very low & 35 & 15.0 \\
\hline \multicolumn{3}{|l|}{ Profiles } \\
\hline 1 (with Guilt) & 220 & 94.0 \\
\hline 2 (without Guilt) & 14 & 6.0 \\
\hline
\end{tabular}

Level distribution by percentiles: Very low: $\leq 10$; Low: 11-33; Medium: 34-66; High: 67-89 and Critical: 90-99. Without Guilt: $\leq 89$; with Guilt: 90-99.

SOURCE: Authors 
expected result was obtained for the Enthusiasm Towards the Job domain, with negative scores when compared with the other domains, while the correlations among the remaining domains scored positive, with the highest correlation found between Psychological Exhaustion and Indolence, and Guilt and Indolence.

Reliability results using Cronbach's alpha coefficient for Enthusiasm Towards the Job, Psychological Exhaustion, Indolence and Guilt are reliable, as is also the case for overall Cronbach's alpha coefficient for all the items, where results show that the test is reliable for the study of BOS in each of the domains. The study by Peñalosa shows a Cronbach alpha value of 0.748 for the SBI as well as for each of the domains, as follows: Enthusiasm Towards the Job, 0.754; Psychological Exhaustion, 0.806; Indolence, 0.715; and Cuilt, 0,814 (36). In contrast, the study by Córdoba et al., in which the authors used the Maslach Burnout Inventory-Human Services Survey (MBI-HSS) for test adaptation and validation in Cali, Colombia, with 314 healthcare professionals, found the following internal consistency using Cronbach's alpha coefficient: 0.77 for the MBI-HSS, and 0.83 for emotional exhaustion, 0.52 for depersonalization, and 0.57 for personal accomplishment. Of these, the latter two show an inadequately low coefficient for BOS reliability using the MBI-HSS in the Cali-Colombia sample (37). Regarding scale reliability using Cronbach's alpha coefficient in the four domains as well as for the overall SBI result, adequate values above 0.7 were obtained. Therefore, it can be concluded that the scale is reliable for assessing burnout syndrome (BOS) and can be used to make an adequate diagnosis according to profile 1 (without Guilt) or profile 2 (with Guilt).

In their study with 110 Mexican physicians, Gil-Monte et al. carried out a factorial validity test of the SBI using the maximum likelihood $(\mathrm{ML})$, with the following results, considered sufficient: $\mathrm{X} 2$ /gl=1.37 and GFI: 0.83 . The model was found to be adequate when considering the RMSEA indices: $0.061 ; \mathrm{NFI}: 0.9$; CFI: 0.92 and PNFI: 0.65; factorial loads were significant, and item 11 under the Indolence domain was the lowest at $\Lambda: 0,25$. Reliability indices using Cronbach's alpha for Enthusiasm Toward the Job (0.72), Psychological Exhaustion (0.86), Indolence (0.75) and Guilt (0.79) show that the SBI is a valid and reliable tool to assess BOS in Mexican physicians (21); Gil Montes et al. showed similar results in a study with 720 nurses in Valencia, Spain, showing validity and reliability of $\mathrm{BOS} \underline{(38)}$.

Strengths of this study include the following: several medical-surgical specialties in 14 healthcare institutions were considered; reviewer bias was controlled by means of training in the SBI of the psychologist in charge of collecting the data face-to-face; a pilot test was carried out in order to avoid questionnaire bias; to avoid response bias, privacy was ensured, with no audio or video recording; personal data confidentiality was secured. Although convenience sampling was used, the selected participants met the inclusion criteria and they all agreed to participate by signing an informed consent. Polychoric matrices were used for the factorial analysis, allowing the use of quantitative variables with ordinal response options (Likert-type) for the tool. A validated and reliable tool is now available for future BOS studies designed to provide information for diagnosis and prevention and intervention plans.

This study contributes to the knowledge about this phenomenon at an institutional, regional and national level, for future design of occupational wellness and mental health plans targeted at healthcare personnel working with patients, in order to enhance overall performance in their personal, family, social and work life.

Weaknesses were found in terms of selection bias, given that only surgical specialists were considered and selection was non-randomized, which means that results cannot be extrapolated. The study was conductedin the Medellín metropolitan area, hence the recommendation to conduct further research at a broader regional and national level. It is worth considering that participants with BOS might be more inclined to participate, leading to overestimation of the results.

Given that the participants were not involved in assessing relevance or thoroughness of the SBI content and only the judgement of the seven experts was taken into account, there was a limitation in terms of content validity.

Further studies including test-retest, convergent, divergent and discriminating construct validity and sensitivity to change are needed; fit tests show that the model is acceptable; an exploratory factorial analysis to determine whether the construct behaves differently in the assessed population would be an important component in a future study.

Prospects for research include a national study of the healthcare population in order to identify the population at risk, BOS prevalence and incidence at a regional and national level, with the aim of creating awareness among scientific societies, healthcare institutions and occupational risk management organizations (ARL).

The results found by this study for content validity are acceptable and applicable to all items and the four domains. Construct validity as determined by the CFA is acceptable, as is also the case with the internal consistency-type reliability results for BOS study in surgical specialists. Specialties in which BOS was found, in order, were: surgery, $22.2 \%$; obstetrics and gynecology, $22.2 \%$; orthopedics, $13.9 \%$; anesthesiology, $11.1 \%$; and urology $11.1 \%$. The results of this study pave the way for future research on BOS in different healthcare institutions, thus expanding the study population working in direct contact with patients.

\section{ETHICAL RESPONSIBILITIES}

\section{Ethics committee endorsement}

This study on SBI validation and reliability was approved by the Ethics Committee 
of the Universidad de Antioquia Medical Research Institute, as stated in minutes No. 088 of May 24, 2018, and by the committees of each of the participating institutions.

\section{Human and animal protection}

The authors declare that no human or animal experiments were conducted for this research. The authors declare that all of the procedures used were in compliance with the ethical standards of the responsible human experimentation committee, the World Medical Association and the Declaration of Helsinki.

\section{Data confidentiality}

The authors declare having followed the protocols of their institution regarding patient data disclosure.

\section{Right to privacy and informed consent}

The authors declare that no patient data appear in this article. The authors obtained informed consents from the patients and/ or subjects mentioned in this paper. The informed consent forms are kept by the corresponding author.

\section{ACKNOWLEDGEMENTS}

\section{Authors' contributions}

LMGB: Original project conception, study planning, data collection, data analysis, interpretation of the results and final drafting of the manuscript.

DCAA: Study planning, data analysis, interpretation of the results and review of the final drafting of the manuscript.

CMZR: Study planning, data collection, data analysis, interpretation of the results and final review of the manuscript.

HIGG: study planning, data analysis, interpretation of the results, review of the drafting and final approval of the manuscript.

\section{Assistance for the study}

None declared.

\section{Financial support and sponsorship}

None declared.

\section{Conflict of interest}

None declared.

\section{Submissions}

None declared.

\section{Appreciation}

To the participating healthcare institutions: Clínica de la Policía, Clínica Noel, Clínica Norte de Bello, Clínica Rosario sede centro, Hospital General de Medellín, Hospital Infantil Concejo de Medellín, Hospital La María, Hospital Marco Fidel Suárez de Bello, Hospital San Juan de Dios Rionegro, Hospital San Rafael de Itagüí, Hospital San Vicente de Paúl de Caldas, IPS Universitaria Clínica León XIII, Unidad Hospitalaria Metrosalud Belén and Manrique. To the participating surgical specialists.

\section{REFERENCES}

1. Maslach C, Jackson SE, Leiter MP. The Maslach Burnout Inventory. Third Edit. 1986.

2. Maslach C, Jackson SE, Maslach C, Jackson SE. Patterns of burnout among a national sample of public contact workers. J Health Hum Resour Adm. 1984;7(2):189-212.

3. Maslach C, Schaufeli WB, Leiter MP. Job Burnout. Annu Rev Psychol. 2001;53:397-
422. doi: https://doi.org/10.1146/annurev. psych.52.1.397

4. Freudenberger H]. Staff Burn-Out. ] Soc Issues. 1974;30(1):159-65. doi: https://doi.org/10.1111/j.1540-4560.1974.tboo706.x

5. World Health Orgnization (WHO). Report 2000. Health Systems: Improving Performance. Vol. 78, Ginebra; 2000.

6. World Health Organization (WHO). Burnout an "occupational phenomenon": International Classification of Diseases [internet]. 2019 [cited: 2019 may. 28]. Available at: https://www.who.int/news/ item/28-05-2019-burn-out-an-occupational-phenomenon-international-classification-of-diseases. 2019.

7. Organización Mundial de la Salud. Informe sobre la salud en el mundo 2001. Salud mental: nuevos conocimientos, nuevas esperanzas [Internet]. 2001 [cited:: 2001 oct.]. Available at: https://www.who.int/whr/2001/en/whro1_ es.pdf?ua $=1$

8. Guevara CA, Henao DP. Síndrome de desgaste profesional en médicos internos y residentes. Hospital Universitario del Valle, Cali, 2002. Colombia Médica. 2004; 35:173-8.

9. Paredes OL. Prevalencia del Síndrome de Burnout en residentes de especialidades médico quirúrgicas, su relación con el bienestar psicológico y con variables sociodemográficas y laborales. Rev Med la Fac Med. 2008;16(1):25-32.

10. Gil-Monte PR. CESQT Cuestionario para la evaluación del síndrome de quemarse por el trabajo. Manual Ediciones TEA; 2011. doi: https://doi.org/10.11144//averiana.upsy9-1.vfce

11. Gil-Monte PR, Unda Rojas S, Sandoval Ocaña JI. Validez factorial del "Cuestionario para la Evaluación del Síndrome de Quemarse por el Trabajo" (CESQT) en una muestra de maestros mexicanos. Salud Ment. 2009;32(3):205-14.

12. Gil-Monte PR. El síndrome de quemarse por el trabajo (síndrome de Burnout) en profesionales de enfermería. Rev Electrónica Int PSY. 2003;1(1):19-33.

13. Gil-Monte PR, Carlotto MS CCS. Validation of the Brazilian version of the "Spanish Burnout Inventory" in teachers. Rev Saude Publica. 2010;44(1):140-7.

14. Gil-Monte P, Unda S, Sandoval O. Validez factorial del Cuestionario para la Evaluación del 
Síndrome de Quemarse por el Trabajo (CESQT). Salud Ment. 2009;32(3):205-14.

15. Muthén LK, Muthén BO. Mplus Statical Analysis with latent variables User's Guide. 2017.

16. Muñiz ]. Teoría clásica de los test. Madrid: Pirámide, 2000.

17. Ferrando PJ. El análisis factorial como técnica de investigación en psicología. Papeles del Psicólogo. 2010;31(1):18-33.

18. Streiner DL, Norman GR, Cairney ]. Health measurement scales, a practical guide to their development and use. Fifth Edit. Canadá: Oxford University Press; 2015. doi: https://doi. org/10.1093/med/9780199685219.001.0001

19. Streiner DL. Starting at the beginning: An introduction to coefficient alpha and internal consistency. ] Personality Assess. 2003;80(1):99-103. doi: https://doi. org/10.1207/S15327752]PA8001_18

20. Campo-Arias A, Oviedo HC. Propiedades psicométricas de una escala: La Consistencia Interna. Rev. Salud Pública. 2008;10(5):8319. doi: https://doi.org/10.1590/S0124$\underline{00642008000500015}$

21. Gil-Monte PR, Zúñiga-Caballero LC. Validez factorial del Cuestionario para la Evaluación del Síndrome de Quemarse por el Trabajo (CESQT) en una muestra de médicos mexicanos. Univ. Psychol. 2010;9(1):169-78. doi: https://doi.org/10.11144/Javeriana.upsy9-1.vfce

22. De Vet H.C.W, Terwee C.B, Mokkink L.B, Knol D.L. Measurement in Medicine, A Practical guides. First published. USA: Cambridge University Press; 2011. doi: https://doi. org/10.1017/CBO9780511996214
23. Luján-Tangarife JA, Cardona-Arias JA. Construcción y validación de escalas de medición en salud: Revisión de propiedades psicométricas. Arch Med. 2015;11(3):1-10.

24. Pedrosa I, Suárez-Álvarez ], García-Cueto E. Evidencias sobre la validez de contenido: Avances teóricos y métodos para su estimación. Acción Psicológica]. 2014;10(2):3-20. doi: https://doi.org/10.5944/ap.10.2.11820

25. Escobar-Pérez ], Cuervo-Martínez Á. Validez de contenido y juicio de expertos: Una aproximación a su utilización. Av en Medición. 2008;6:27-36.

26. Ayre C, Scally A]. Critical values for Lawshe's content validity ratio: Revisiting the original methods of calculation. Meas Eval Couns Dev. 2013;41(1):79-86. doi: https://doi. org/10.1177/0748175613513808

27. Lawshe CH. A Quantitative approach to content validity. Pers Psychol. 1975;28:563-75. doi: https:// doi.org/10.1111/j.1744-6570.1975.tb01393.x

28. Wilson FR, Pan W, Schumsky DA. Recalculation of the critical values for Lawshe's content validity ratio. Meas Eval Couns Dev. 2012;43(3):197-210. doi: https://doi. org/10.1177/0748175612440286

29. Kendall MG, Smith BB. The problem of $m$ rankings. Ann Math Stat. 1939;10(3):275-87. doi: https://doi.org/10.1214/aoms/1177732186

30. Suh Y. The performance of maximum likelihood and weighted least square mean and variance adjusted estimators in testing differential item functioning with nonnormal trait distributions. Struct Equ Model A Multidiscip J. 2015;22(January 2015):568-80. doi: https:// doi.org/10.1080/10705511.2014.937669
31. Brown TA. Confirmatory factor analysis for applied research. 2nd Edi. USA: Guilford Press; 2015.

32. Schreiber JB, Nora A, Stage FK, Barlow EA, King ]. Reporting structural equation modeling and confirmatory factor analysis results : A Review. J Educ Res. 2006;99(6):323-37. doi: https://doi.org/10.3200/JOER.99.6.323-338

33. Sánchez R, Echeverry ]. Validación de escalas de medición en salud. Rev Salud Pública. 2004;6(3):302-18. doi: https://doi.org/10.1590/ $\underline{\text { So124-00642004000300006 }}$

34. Maslach C, Jackson SE, Leiter MP. The Maslach Burnout Inventory Manual. En: Evaluating Stress: A Book of Resourses [Internet]. 1997 [cited: 2018 may. 25]. p. 191-218. Available at: https://www.researchgate.net/publication/277816643_The_Maslach_Burnout_Inventory_Manual

35. Gil-Monte PR, Peiró JM. Validez factorial del Maslach Burnout Inventory en una muestra multiocupacional. Psicothema. 1999;11(3):679-89.

36. Peñaloza S. Validez y confiabilidad del CESQT en profesionales de enfermeria. Tesis de Maestría, Universidad Nacional, Bogotá; 2008.

37. Córdoba L, Tamayo JA, Conzález MA, Martínez MI, Rosales A, Barbato SH. Adaptation and validation of the Maslach Burnout Inventory-Human Services Survey in Cali, Colombia. Colomb Med. 2011;42(3):286-93. doi: https://doi.org/10.25100/cm.v42i3.874

38. Gil-Monte PR, Manzano-García C. Psychometric properties of the Spanish Burnout Inventory among staff nurses. ] Psychiatr Ment Health Nurs. 2015;22:756-63. doi: https://doi. org/10.1111/jpm.12255 